\title{
Quality of life after lumbar microscopic discectomy
}

\author{
Sagar Koirala $M C h^{1}$, Subash Lohani $M S^{2}$, Suresh Bishokarma $\mathrm{MCh}^{3}$, Sharad Koirala $\mathrm{MPH}^{4}$, \\ Pratyush Shrestha $M \boldsymbol{C h}^{5}$ \\ 1,2,3,5 Neurosurgery, Upendra Devkota Memorial National Institute of Neurological and Allied Sciences \\ ${ }^{4}$ Community Medicine, Gandaki Medical College
}

Date of submission: $21^{\text {st }}$ November 2020

Date of acceptance: $31^{\text {st }}$ January 2021

Date of publication: $1^{\text {st }}$ March 2021

\section{Abstract}

Introduction: Lumbar disc herniation also known as prolapsed intervertebral disc is one of the well-known causes of low back pain. Among various modalities of treatment, surgery is often kept as the last resort when conservative treatment fails. Conventional surgical methods have been replaced by minimally invasive surgeries like microscopic, endoscopic and percutaneous lumbar discectomy in the hopes of decreasing post-operative pain. However, it is not uncommon for patient to have residual pain even after discectomy. Patients also complains of reduced quality of life (QOL). SF-36 is a standardized questionnaire for measuring QOL. Few studies have used this questionnaire to look into QOL of these patients but no such study is available in Nepalese perspective.

Methodology: A prospective cross-sectional study was conducted among all patients undergoing single level unilateral microscopic lumbar discectomy in Upendra Devkota Memorial National Institute of Neurological Sciences from February 1st 2017 to January 31 2018. After taking informed consent, subjects were asked to respond to the preformed questionnaire and SF-36 survey. Interviews were individually conducted by the same investigator at two different time points: i) before lumbar discectomy. ii) 3 months after lumbar discectomy. QOL scores before and after were compared.

Results: Total of 50 patients meeting the inclusion criteria were studied. The mean age of the study group was 38.7 \pm 9.9 years with male preponderance of $76 \%$. The median duration of exacerbation of symptoms was 4 weeks. Along with pain, $64 \%$ had sensory deficit whereas $52 \%$ had motor deficit. Surgery led to significant improvement in pain score as well as marked improvement of SF 36 quality of life score at 3 months of surgery. However, age, gender, duration of symptoms or presence of sensory or motor deficit before surgery did not predict improvement in overall QOL.

Conclusion: Patients undergoing microscopic lumbar discectomy for prolapsed intervertebral disc have significant improvement in pain score and QOL after 3 months of surgery.

Key words: Microscopic lumbar discectomy, Prolapsed intervertebral disc, Quality of life (QOL), SF-36

Access this article online
Website: https://www.nepjol.info/index.php/NJN
HOI: https://doi.org/10.3126/njn.v18i1.34941
Koirala S, Lohani S, Bishokarma S, Koirala S, Shrestha P. Quality
of life after lumbar microsciopic discectomy. NJNS. 2021;18(1):33-
38.

'ORCID id: 0000-0003-4625-2011

2ORCID id: 0000-0001-7306-5532

${ }^{3}$ ORCID id: 0000-0001-9448-842X

${ }^{4}$ ORCID id: 0000-0001-9383-8002

${ }^{5}$ ORCID id: 0000-0003-0469-2131

Address for correspondence:

Sagar Koirala MS, MCh

Consultant Neurosurgeon,

Upendra Devkota Memorial National Institute of Neurological and

Allied Sciences,

Kathmandu University,

Bansbari, Kathmandu, Nepal

E-mail: sagarkoirala85@gmail.com

\section{Introduction}

Lumbar disc herniation also known as prolapsed intervertebral disc (PIVD) is one of the well-known causes of low back pain. Various methods of treatment ranging from medication, physiotherapy, local infiltration to surgery have been advocated. Among these modalities surgery is often kept as the last resort when conservative treatment fails. ${ }^{1}$ However, it is not uncommon for patient to have residual pain even after discectomy. ${ }^{2}$ Patients also complains of reduced quality of life (QOL). ${ }^{3}$

Copyright (C) 2021 Nepalese Society of Neurosurgeons (NESON)

ISSN: 1813-1948 (Print), 1813-1956 (Online)

(i) (8) This work is licensed under a Creative Commons Attribution-Non Commercial 4.0 International License. 


\section{Koirala et al}

There have been very few studies looking into the postoperative quality of life of these patients in Nepalese population. ${ }^{4}$ There are various QOL related questionnaires available. Among them the Short Form-36(SF-36) is a standardized questionnaire for measuring QOL. ${ }^{5}$ The SF-36 has been well validated in Asia and the Indian subcontinent. ${ }^{5,6}$

\section{Materials and methods}

A prospective, cross sectional, analytical study was conducted from $1^{\text {st }}$ February 2017 to $31^{\text {st }}$ January 2018. All patients undergoing single level microscopic lumbar discectomy during the study period were included in the study. Patients who had additional procedure like facetectomy, bilateral fenestration, instrumentation/ grafts, previously operated at other spinous level, recurrent cases and those not willing to take part in the study were excluded. Non-probability purposive sampling technique was adopted to select the required samples. SF36 questionnaire was used to assess the quality of life before and 3 months after microscopic lumbar discectomy. Numeric pain score was used to assess improvement of pain.

This study was performed after their approval of institutional review board of Upendra Devkota Memorial National institute of Neurological and Allied Sciences, Bansbari, Kathmandu, Nepal.

Analysis was done using Statistical Package for Social Sciences (SPSS) version 20.0 (SPSS Inc., Chicago, IL, USA). Shapiro- Wilk test was used to verify any departures from normality. In case of normal distribution, data was summarized in terms of mean and standard deviation. Where data was found to be skewed, results were summarized as median and ranges. The change of QOL across time in study participants was determined using paired sample t test or Wilcoxon Signed Rank test depending on the normality of the distribution of SF-36 scores. Attempts were also made to assess proportion of patients who had reduced QOL and were compared with patient without reduced QOL scores on pre-surgical variables. The association was assessed using a t-test (in case of continuous variables) or chi squares (in case of categorical variables). Variables were also entered in multiple linear regression analysis to determine independent predictor of poorer QOL. The level of significance was chosen at 0.05 .

\section{Results}

A total of 50 patients were included in the study. The mean age was 38.7 years with standard deviation of 9.9 years with range from 22 years to 72 years.

Majority of patients were males (76\%) compared to females $(24 \%)$. Lumbar disc herniation between $4^{\text {th }}$ and $5^{\text {th }}$ vertebrae were 26 in number and between $5^{\text {th }}$ and first sacral vertebrae were 24 , each level accounting to almost $50 \%$.

Majority of patients were farmers $(20 \%, n=10)$, followed by those doing household work $(18 \%, n=9)$ as shown in figure 1.

Median duration of exacerbation of radicular pain was 4 weeks (range 1-16 weeks). A total of 32 patients had evidence of sensory deficit (64\%) whereas 26 patients also had a motor deficit (52\%).

The overall pain scores prior to surgery was rather high as indicated in the table 1. Shapiro-wilk test of normality indicated a non-normal distribution ( $\mathrm{p}$ value 0.02 ), hence this variable was interpreted in the context of non-parametric statistics. The median pre-surgery pain score was 8 (range 6-10).

Pain scores after surgery appeared to be visually much lower. Again, this variable had a non-normal distribution (Shapiro-Wilk p value 0.01). The median post-surgery pain score was 1 (range $0-5$ ).

We hypothesized that surgery led to significant improvements in the pain score. Given the ordinal (nonnumeric) nature of the variable (pain score), we tested the difference of the pain score before and after surgery using Wilcoxon matched-pair signed rank test. The $p$ value of the Wilcoxon signed rank test was $<0.01$, thus rejecting the null hypothesis that surgery had no effect on pain scores.

First, we sought to check for the reliability of the SF36 instrument in our study population. For this we checked inter-domain correlation using Spearman's rho statistic and internal consistency using Cronbach's alpha where a value of $>0.7$ was deemed to indicate good consistency.

As shown in table 3 and 4, the instrument performed well in terms of inter-domain correlation coefficient as well as Cronbach's alpha. This suggested that SF36 was fairly reliable in measurement of QOL in our study population.

Table 5 shows the QOL scores before and after surgery among the different domains and overall in the study population. The quality of life scores is much lower compared to QOL scores across various domains and overall score after surgery.

Test of significance between pre and post scores was done with matched paired t-test. All significance levels are two sided and the level of $\alpha$ chosen at 0.05 .

Table 6 shows the comparison between pre and postsurgical QOL scores, overall and across various domains in the study population. We used matched paired t-test to assess for significance of this change. There was a significant improvement in the QOL scores in each of 
QOL after microdiscectomy

these domains as well as overall as suggested by $\mathrm{p}$ value of $<0.01$ in all cases.

Next, we attempted multivariate linear and ordinal regression models to identify variables that significantly predicted a greater improvement in overall quality of life scores ( $\Delta$ QOL). However, there was no significant impact of age, gender, duration of exacerbation of pain or presence of sensory or motor deficit that predicted a significant improvement in overall QOL.

\begin{tabular}{|c|c|c|}
\hline Pain Score & Frequency & Percentage \\
\hline 6 & 3 & $6 \%$ \\
\hline 7 & 9 & $18 \%$ \\
\hline 8 & 19 & $38 \%$ \\
\hline 9 & 18 & $36 \%$ \\
\hline 10 & 1 & $2 \%$ \\
\hline
\end{tabular}

Table 1: Summary of pain score prior to surgery

\begin{tabular}{c|c|c|}
\hline Pain Score & Frequency & Percentage \\
\hline 0 & 6 & $12 \%$ \\
1 & 26 & $52 \%$ \\
2 & 13 & $26 \%$ \\
3 & 3 & $6 \%$ \\
\hline 5 & 2 & $4 \%$ \\
\hline
\end{tabular}

Table 2: Summary of pain score after surgery

\begin{tabular}{l|c|c}
\hline \multicolumn{1}{|c|}{ QOL domain } & Mean & $\begin{array}{c}\text { Correlation with } \\
\text { Overall Score* }\end{array}$ \\
\hline $\begin{array}{l}\text { Physical Functioning } \\
\text { Role Limitations due to } \\
\text { Physical health }\end{array}$ & 37.8 & 0.79 \\
\hline $\begin{array}{l}\text { Bodily Pain } \\
\text { Social Functioning }\end{array}$ & 19.1 & 0.66 \\
\hline Mental Health & 30.5 & 0.82 \\
\hline $\begin{array}{l}\text { Role limitation due to } \\
\text { emotional Problems }\end{array}$ & 42.9 & 0.87 \\
\hline Vitality & 32 & 0.54 \\
\hline General Health & 36.8 & 0.83 \\
\hline
\end{tabular}

Table 3: Inter domain correlation coefficient between various QOL domains and the overall score. * Computed using Spearman's rho function.

\begin{tabular}{|c|c|}
\hline Domain & Cronbach's alpha \\
\hline PF & 0.93 \\
RP & 0.93 \\
BP & 0.92 \\
GH & 0.92 \\
VE & 0.94 \\
RE & 0.93 \\
SF & 0.93 \\
\hline MH & 0.92 \\
\hline Overall & 0.92 \\
\hline
\end{tabular}

Table 4: Internal Consistency of SF36 instrument in the study population using Cronbach's alpha

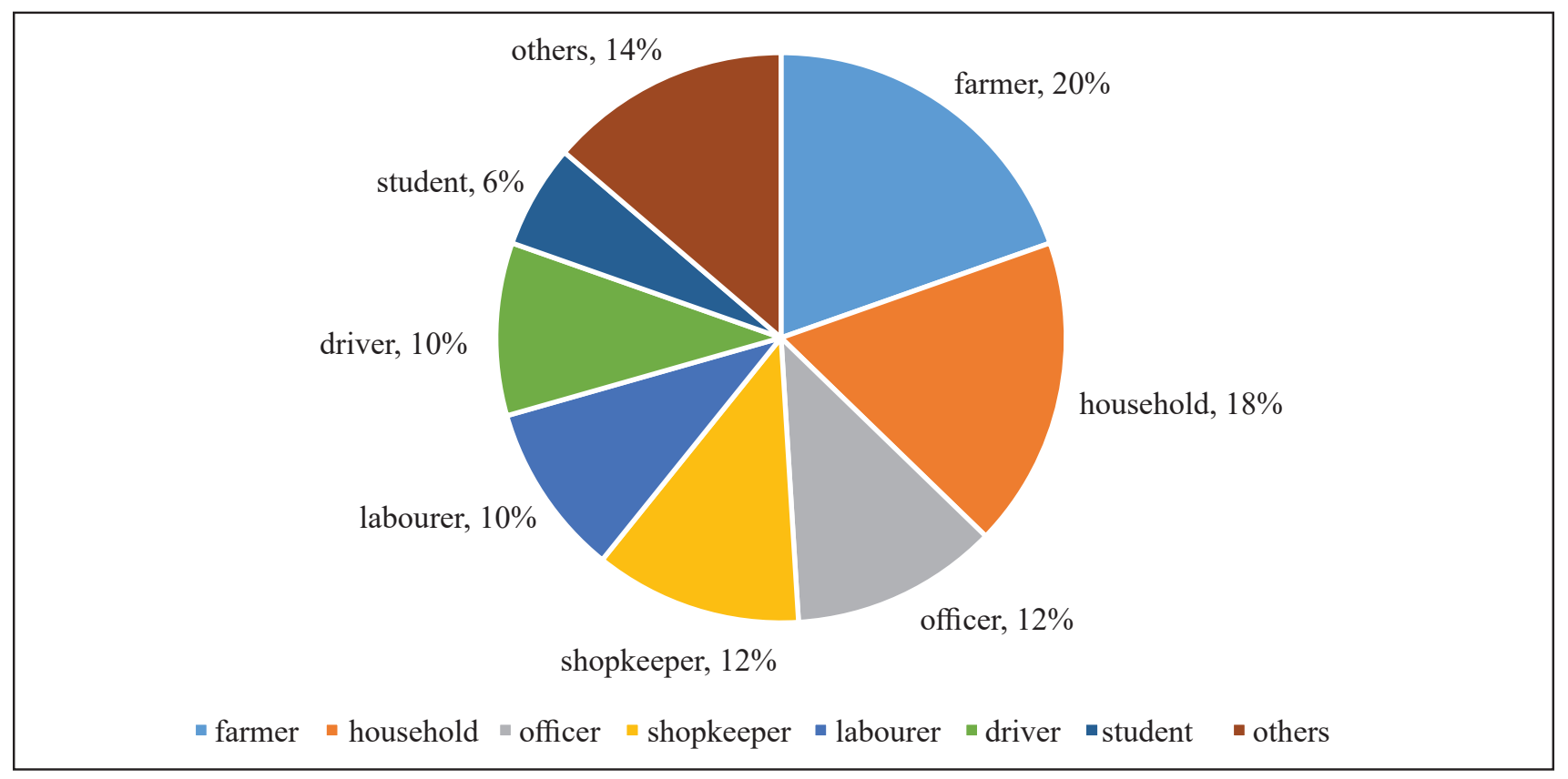

Figure 1: Pie diagram showing occupation distribution among patients. 


\section{Koirala et al}

\begin{tabular}{|l|c|c|c|c|c|c|}
\hline & \multicolumn{3}{|c|}{ scores before surgery } & \multicolumn{4}{c}{ after surgery } \\
\hline Categories & Minimum & Maximum & Mean \pm SD & Minimum & Maximum & Mean \pm SD \\
\hline Physical Functioning & 10 & 75 & $37.8 \pm 16.7$ & 35 & 100 & $84.9 \pm 13.5$ \\
\hline Role Physical & 0 & 50 & $23.4 \pm 12.6$ & 25 & 100 & $80.4 \pm 17.9$ \\
\hline Bodily Pain & 0 & 62.5 & $19.1 \pm 12.8$ & 25 & 100 & $77.5 \pm 16.8$ \\
\hline General Health & 10 & 60 & $30.7 \pm 9.8$ & 30 & 95 & $72.1 \pm 12.9$ \\
\hline Vitality & 6.25 & 62.5 & $36.8 \pm 13$ & 50 & 93.75 & $75.9 \pm 8.6$ \\
\hline Role Emotional & 0 & 75 & $32 \pm 17.5$ & 0 & 100 & $85.5 \pm 22.6$ \\
\hline Social Functioning & 12.5 & 62.5 & $30.5 \pm 12.7$ & 25 & 100 & $82.8 \pm 16.7$ \\
\hline Mental Health & 15 & 70 & $42.9 \pm 11.7$ & 25 & 95 & $77 \pm 13.9$ \\
\hline Overall & 6.7 & 61.6 & $31.6 \pm 10.5$ & 26.9 & 97.9 & $79.5 \pm 13.6$ \\
\hline
\end{tabular}

Table 5: SF36 QOL scores before and after surgery

\begin{tabular}{|c|c|c|c|}
\hline Categories & Mean before surgery & Mean after Surgery & P value* $^{*}$ \\
\hline Physical Functioning & 37.8 & 84.9 & $<0.01$ \\
\hline Role Physical & 23.4 & 80.4 & $<0.01$ \\
\hline Bodily Pain & 19.1 & 77.5 & $<0.01$ \\
\hline General Health & 30.7 & 72.1 & $<0.01$ \\
\hline Vitality & 36.8 & 75.9 & $<0.01$ \\
\hline Social Functioning & 30.5 & 82.8 & $<0.01$ \\
\hline Role Emotional & 32 & 85.5 & $<0.01$ \\
\hline Mental Health & 42.9 & 77 & $<0.01$ \\
\hline Overall & 61.6 & 79.5 & $<0.01$ \\
\hline
\end{tabular}

Table 6: Comparison of mean quality of life scores among different SF domains and overall pre and post-surgery.

\section{Discussion}

The response rate to the questionnaire of this study has been $100 \%$ as the patients were interviewed after admission in the ward. These patients were then under follow up at our center after the surgery. Hence there were no drop outs. The other reason is short term follow up done in this study.

Since the pre and postoperative quality of life were evaluated in cross over design of the study, various confounding bias were eliminated. Pain is the major symptom of these patients for which they come to our facility hence the quality of life of these patients are poor to begin with.

Health related quality of life as a means of assessing outcome of any spinal surgery is increasingly used in studies by researchers as it allows objective comparison among the scores before and after surgery as well as the scores can be used to compare outcome across various other study. ${ }^{7-11}$ The SF-36 is advantageous in that it achieves the best balance between length, reliability, validity, and responsiveness. ${ }^{12}$ There are various study which have used SF36 to evaluate QOL among patients with spine disease. ${ }^{13-17}$
The demographic profile as well as male preponderance seen in our study was similar to the systemic review conducted by Jo Jordan and colleagues in 2009 where they found this condition to be common in between 30 to 50 years with male to female ration of $2: 1$. Similarly herniation between 4 th $/ 5$ th lumbar vertebrae was the most common level. ${ }^{17}$

Pain was the main reason for presentation to the hospital. Though the patient had been having on and off pain the mean duration for exacerbation was around 4 weeks. The neurological deficits were mostly found during examination. Patients in this study had marked improvement of pain score as well as QOL score 3 months after undergoing microscopic lumbar discectomy. This is likely because the median pain score, which was 8 before surgery dropped down to 1 at the end of three months. These patients had improvement in all 8 dimensions of quality of life and hence also in overall scores as seen in the result section. The likely cause for improved QOL appears to be due to marked improvement in pain score as pain was the main reason of presentation to the hospital. None of the tested factors predicted improvement of QOL scores in this study. 
For complete assessment of benefits of the surgical intervention, it is essential to provide evidence of the impact on patients in terms of health status and health related quality of life. ${ }^{8}$ Though the study is of short term follow up, it is seen that these patients have benefited in terms of quality of life.

Mottor and colleagues did a similar study where they followed up patients with SF36 questionnaire at 1moth, 6 month, 1 year and 2 year and found significant improvement in QOL scores across all domains compared to preoperative status, more so among patients returning to work. ${ }^{18}$ However in our study we did not look at return to work as a variable.

Not all studies show improvement in quality of life especially in early post-operative months. A four-year monitoring study concluded that the quality of life of patients after a lumbar micro discectomy deteriorates significantly from a physical point of view immediately after it. It normalizes over the following 6 months, though a certain degree of physical damage still remains. The neurogenic symptoms domain is the least improved dimension of their quality of life: it is very specific and to be evaluated with a special test set. ${ }^{19}$ We did not look into neurological improvement in our study as our study has short follow up.

However, most of the studies showed improvement in each component and overall quality of life. ${ }^{18-20}$ Improvement in terms of mental as well as social wellbeing is seen as all of these factors are attributed to pain. ${ }^{21}$

There is disease specific questionnaire for assessing outcomes for spinal disease. The outcomes may differ if we use those questionnaires. It is still unclear which is the best method. ${ }^{22-24}$ However, the measurement of quality of life provides objective estimations of how and how much the disease influences patients' life and how they cope with it. These evaluations may be used as a baseline and outcome measures and should provide framework to determine the impact of any change on patients' life quality. ${ }^{25,26}$

This study implies that for patient with pain due to prolapsed intervertebral disc, the pain is likely to decrease after surgery and improvement in QOL is expected at 3 months post-surgery. The findings of this study can be used for counselling these subsets of patient before surgery.

The limitation of the study is the short follow up of the patients studied. The neurological outcomes of surgery have not been looked into. The patient selection for surgery, its indication and workup for instability were not performed by the author. Some of the patients were operated without trial of conservative treatment. Various preoperative factors that may affect the post-operative QOL like smoking, history of trauma, failed back syndrome etc. has not been looked into which can be the next step for the author to study. As mentioned above each scale for QOL studies have their own limitation including SF36. The patients with chronic low back pain have sleep disturbances leading to poorer quality of life which the SF36 questionnaire does not include. ${ }^{27}$

\section{Conclusion}

There is improvement of quality of life of patients undergoing microscopic lumbar discectomy at 3 months compared to before surgery based on SF36 scores.

Conflict of Interest: None

Source(s) of support: None

\section{References}

1. Parker SL, Xu R, McGirt MJ, Long DM, Bydon A. Long-term back pain after a single-level discectomy for radiculopathy: incidence and health care cost analysis. J Neurosurgery Spine. 2010;12(2):178-82. https://doi.org/10.1016/j.spinee.2010.10.008

2. Maroon J, Abla A. Microdiscectomy versus chemonucleolysis. Neurosurgery. 1985; 16(5):644-9. https://doi.org/10.1007/978-3-7091-8978-8_9.

3. Patrick DL, Deyo RA, Atlas SJ, Singer DE, Chapin A, Keller RB. Assessing health-related quality of life in patients with sciatica. Spine. 1995;20:1899-909. https://doi.org/10.1097/00007632-199509000-00011

4. Shrestha D, Shrestha R, Dhoju D, Kayastha SR, Jha SC. Study of Clinical Variable Affecting Long Term Outcome after Microdisectomy for Lumbar Disc Herniation. Kathmandu Univ Med J 2015;52(4): 333-40. https://doi.org/10.3126/kumj.v13i4.16833

5. Jenkinson $\mathrm{C}$, Wright L, Coulter A. Criterion validity and reliability of the SF-36 in a population sample. Qual Life Res, 1994;3(1):7-12. https://doi. org/10.1007/BF00647843

6. Sinha R, Heuvel WJ, ArokiasamyP.Validity and Reliability of MOS Short Form Health Survey (SF-36) for Use in India. Indian J Community Med.2013;38(1):22-6. https://doi.org/10.4103/09700218.106623

7. Jordon J, Konstantinou K, O’Dowd J. Herniated lumbar disc. BMJ Clinical Evidence. 2009; 2009: 1118. https://www.ncbi.nlm.nih.gov/ pubmed/21711958

8. Zanoli G, Jonsson B, Stromqvist B. SF-36 scores in degenerative lumbar spine disorders: analysis of prospective data from 451 patients. Acta Orthop. 2006;77(2):298-306. https://doi. org/10.1080/17453670610046064 
9. Zanoli G, Stromqvist B, Jonsson B. Visual analog scales for interpretation of back and leg pain intensity in patients operated for degenerative lumbar spine disorders. Spine.2001;26(21):2375-80. https://doi. org/10.1097/00007632-200111010-00015

10. Zanoli G, Stromqvist B, Padua R, Romanini E. Lessons learned searching for a HRQoL instrument to assess the results of treatment in persons with lumbar disorders. Spine.2000;25(24):3178-85. https://doi. org/10.1097/00007632-200012150-00013

11. Ware JE, Sherbourne CD. The MOS 36-item shortform health survey (SF-36). I. Conceptual framework and item selection. Med Care. 1992;30(6):473-83. https://www.ncbi.nlm.nih.gov/pubmed/1593914

12. Ware JE, Bjorner JB, Kosinski M. Practical implications of item response theory and computerized adaptive testing: a brief summary of ongoing studies of widely used headache impact scales. Med Care. 2000;38(9 Suppl):73-82. https:// www.ncbi.nlm.nih.gov/pubmed/10982092

13. Gatchel RJ, Mayer T, Dersh J, Robinson R, Polatin P. The association of the SF-36 health status survey with 1-year socioeconomic outcomes in a chronically disabled spinal disorder population. Spine. 1999;24(20):2162-70. https://doi. org/10.1097/00007632-199910150-00017

14. Korovessis P, Dimas A, Lambiris E. The significance of correlation of radiographic variables and MOS short-form health survey for clinical decision in symptomatic low back pain patients. Stud Health Technol Inform.2002;91:325-31. https://doi. org/10.1007/s00590-004-0164-Z

15. Fisher C, Noonan V, Bishop P, Boyd M, Fairholm D, Wing $\mathrm{P}$, et al. Outcome evaluation of the operative management of lumbar disc herniation causing sciatica. J Neurosurg. 2004;100 (4 Suppl Spine):317-24. https://doi.org/10.3171/spi.2004.100.4.0317

16. Kosinski MR, Schein JR, Vallow SM, Ascher S, Harte C, Shikiar R, et al. An observational study of healthrelated quality of life and pain outcomes in chronic low back pain patients treated with fentanyl transdermal system. Curr Med Res Opin 2005;21(6):849-62. https://doi.org/10.1185/030079905x46377

17. Bombardier C. Outcome assessments in the evaluation of treatment of spinal disorders: summary and general recommendations. Spine.2000;25(24):3100-3. https:// doi.org/10.1097/00007632-200012150-00003
18. Motter BV, Machado AN, Brandão TK, Ueno FH, Cesar AEM, Rodrigues LMR Quality of life in patients before and after lumbar surgery in different work situations. Columna. 2015;14(3):198-201. https://doi.org/10.1590/s1808-185120151403147815

19. Bošković K, Cigić T, Grajić M, Todorović-Tomašević S, Knežević A. The quality of life of patients after a lumbar microdiscectomy: A four-year monitoring study. Clinical Neurology and Neurosurgery. 2010;112(7) 557-62. https://doi.org/10.1016/j. clineuro.2010.03.014

20. Rosinczuk J, Aleksandra P, Miksiewicz M \& Kołtuniuk Al. The Quality of Life in Patients After Surgical Treatment of a Lumbar Disc Herniation A Preliminary Study. The Journal of Neurological and Neurosurgical Nursing.2017;6:4-10. https://doi. org/10.15225/pnn.2017.6.1.1

21. Farzanegan G, Alghasi M, Safari S. Quality-ofLife Evaluation of Patients Undergoing Lumbar Discectomy Using Short Form 36. Anesth Pain. 2011;1(2): 73-6. https://doi.org/10.5812/aapm.1998

22. Bouchet C, Guillemin F, Briancon S. Nonspecific effects in longitudinal studies: impact on quality of life measures. J Clin Epidemiol. 1996;49(1):15-20. https://doi.org/10.1016/0895-4356(95)00540-4

23. Camilleri-Brennan J, Steele RJ. Measurement of quality of life in surgery. J R Coll Surg Edinb. 1999;44(4):252-9. https://www.ncbi.nlm.nih.gov/ pubmed/0453149

24. Wood-Dauphinee S. Assessing quality of life in clinical research: from where have we come and where are we going? J Clin Epidemiol. 1999;52(4):355-63. https://doi.org/10.1016/s0895-4356(98)00179-6

25. Soler-Soler J, Permanyer-Miralda G. How do changes in lifestyle complement medical treatment in heart failure? Br Heart J 1994;72(3 Suppl):87-91. https:// doi.org/10.1136/hrt.72.3_suppl.s87

26. Weinstein JN, Tosteson TD, Lurie JD, Tosteson NAN, Hanscom B, Skinner JS et al. Surgical vs non-operative treatment for lumbar disk herniation: The spine patient outcomes research trial (SPORT): a randomized trial. JAMA. 2006;296(6):2441-50. https://doi.org/10.1001/jama.296.20.2441

27. Melek S, Hasanefendioğlu Z, Ali M, Incel A, Cimen B, Kanik A et al. Sleep quality in patients with chronic low back pain: A cross-sectional study assessing its relations with pain, functional status and quality of life. Journal of back and musculoskeletal rehabilitation.2015; 28: 433-41. https://doi. org/10.3233/bmr-140537 